\title{
Biological control of fungal phytopathogens: A comprehensive review based on Bacillus species
}

\begin{abstract}
Worldwide, emergence of new resistant fungal phytopathogens and use of chemical fertilizers, pesticides, fungicides for the protection of crops lead to serious environmental issues. Due to these problems, the need to explore alternative management approaches that are not only successful but also less harmful to the environment is of paramount importance. Bacillus species are a good candidate for use as a biocontrol agent against these fungal phytopathogens because they produce various types of antimicrobial substances and their environmentally friendly behavior. This article provides basic knowledge of Bacillus spp. biocontrol agents, tools for identification of their biocontrol agents and techniques for screening of Bacillus spp. against fungal phytopathogens based on current findings. Specifically, if thoroughly explored, Bacillus will remove the existing commonly used control agents such as fungicides, harmful cultural activities of health and control phytopathogens in the ecosystem.
\end{abstract}

Keywords: bacillus, emergence, phytopathogen, biocontrol
Volume 6 Issue 2 - 202I

\author{
Muddasir Khan,' Muhammad Salman,' Sohail \\ Ahmad Jan, ${ }^{2}$ Zabta Khan Shinwari ${ }^{3,4}$ \\ 'Department of Health and Biological Sciences, Abasyn \\ University Peshawar, Pakistan \\ 2Department of Bioinformatics and Biosciences, Capital \\ University of Science and Technology, Pakistan \\ ${ }^{3}$ Department of Plant Sciences, Quaid-i-Azam University, \\ Pakistan \\ ${ }^{4}$ Pakistan Academy of Sciences, Pakistan
}

Correspondence: Muddasir Khan, Department of Health and Biological Sciences, Abasyn University Peshawar, Khyber Pakhtunkhwa, Pakistan, Tel 0092-3025678947, ORCID 0000 000I-6545-76I6, Email muddasir.khan0302@gmail.com

Received: March 05, 202I | Published: April 16, 202 I

\section{Introduction}

Globally, biotic stresses such as pests and pathogens are main factors of threat for the production of crops and a recently study reported that crop loss about $8-40 \%$ worldwide is due to fungal pathogens. ${ }^{1}$ Among these plant diseases, the most important economic pathogen is Fusarium species, which cause a wide range of diseases including wilts, head blights, fruit rots, and root rots. The population of disease caused by Fusarium graminearum was reported in the Netherlands, western Canada, Great Britain, Germany, northwest Europe and North America. ${ }^{2}$ Globally, a major crops loss is due to the disease cause by Rhizoctonia solani which is a most important fungal phytopathogen belongs to genus Rhizoctonia. This fungus is the prominent causative agent of soil-borne diseases including root rots, wilts and seedling disease. ${ }^{3}$ Additionally, grain quality reduction fungus named $F$. graminearum produce mycotoxin such as deoxynivalenol (DON), trichothecenesnivalenol (NIV), its derivatives 3-and 15- acetyldeoxynivalenol (3-ADON, 15-ADON) which cause diseases in plants, immunosuppression and neurological disorder in humans and animals. ${ }^{4}$ Based on scientific and economic importance, $F$. graminearum is the fourth important fungal phytopathogen. It affects cereal crops and a major source of contamination in food grain. The associated symptoms of this fungal infection are premature bleaching due to which yield and quality of the grain is reduce. ${ }^{1} R$. solani symptoms on varied hosts include crown rot, root rot, seed rot, hypocotyl rot, limb rot, stem rot, stem canker, pod rot, pre- \& postemergence damping off, black scurf and seedling blight. ${ }^{3}$ To monitor these plants diseases, therefore, exploring alternative management approaches which are not only successful but also less harmful to the environment.

From the last three decades, various bio-control strategies have been developed in the form of chemical fertilizers, pesticides, and fungicides against pests and fungal phytopathogens for the protection of crops. The use of these chemicals and agents lead to serious environmental issues. The plant growth promoting rhizobacteria (PGPR) offer an attraction to replace these chemicals and fertilizers by the biological agents due to their wide range availability, biocontrol agent's production and environmental friendly behavior. ${ }^{5,6}$ The PGPR prevents the growth of the phytopathogens through their antagonistic activity. They suppress the growth of the pathogen and produce antibiotics, organic volatile compounds, hydrolytic enzymes, extracellular antifungal metabolites, cellulolytic enzymes such as proteases, celluloses, chitinases and cyanides. The PGPR also reduces the growth of the phytopathogens through nutrient competition. $^{7}$ Among the genera of bacteria, the reported most common rhizobacteria include; Bacillus, Pseudomonas, Arthrobacter, Agrobacterium, Rhizobia, Alcaligenes, Azotobacter, Mycobacterium, Flavobacter, Cellulomonas, and Micrococcus. ${ }^{8}$ The PGPR is a good candidate to use as bio-control agents against phytopathogens because of their environmentally friendly behavior. This prospective article provides basic literature knowledge about certain Bacillus species as bio-control agents against fungal phytopathogens like Fusarium graminearum and Rhizoctonia solani.

\section{Bacillus species against phytopathogens}

In the field of biopesticides, the Bacillus species and other PGPR play an important role because they produce a variety of antimicrobial agents including lipopeptides, antibiotics, and enzymes which promote the growth of plants and inhibit the pathogenic microorganisms. ${ }^{9}$ The Bacillus species are found mostly in soil and produce metabolites, which have antibiotic properties and are capable to reduce or suppress the growth of another microorganism..$^{10}$ Bacillus species also produce some volatile agents to promote the plant defense mechanism. Through the biocontrol activity of Bacillus species, mostly bacterial and fungal phytopathogens have been controlled and effective against the protection of plants from diseases. The antimicrobial substances produced by Bacillus species include; subtilin, bacilysin, mycobacillin, bacillomycin, mycosubtilin, iturin, fengycin, and surfactin which has both antifungal and antibacterial activity. ${ }^{1}$ Bacillus species are a good candidate for use as a biocontrol agent because they produce various types of antimicrobial substances and their environmentally friendly behavior. 


\section{Biocontrol agents of Bacillus species}

Bacillus species produce various types of biocontrol agents, which are differentiated by their chemical structure, ${ }^{11}$ among these the fengycins, iturins and surfactins are reported in various studies conducted by researchers. ${ }^{1}$

Fengycin: Fengycin is a cyclic lipodecapeptide composed of $\beta$-hydroxy fatty acid with 16-19 carbon atoms in their side chain. ${ }^{11}$ According to the previously reported study, the fengycin is mostly produced by Bacillus amyloliquefaciens and Bacillus subtilis. ${ }^{12,13}$ Fengycin inhibits the growth of filamentous fungi. They act on the biological membranes and completely disrupt the membranes in different concentration, also inhibits the fungal enzymes such as aromatase and phospholipase A2. ${ }^{14}$ Fengycin promotes the growth of the plant ${ }^{15}$ and effective against various type of fungus including Magnaporthegrisea, Plasmodiophora brassicae, Botryosphaeria dothidea, C. gloeosporiodes, F. verticillioides, F. solani, F. solani $f$. sp. radicicola, F.oxysporum, F.oxysporum $f$. sp. spinaciae, Fverticillioides and F.graminearum. ${ }^{16-20}$ Fengycins inhibit the growth of $F$. graminearum by disrupting their cell membrane permeability; the inhibition depends upon the concentration of fengycin. ${ }^{21}$

Iturin: Iturin is anamphiphilic compounds having C13-to-C17 $\beta$-amino fatty acid chain connected to heptapeptide backbone and produce ion-conducting pores inside the fungal cell membranes due to their high fungitoxic characteristics. ${ }^{22}$ Iturin mostly produce by Bacillus subtilis and Bacillus amyloliquefaciens strains according to the previously reported studies. ${ }^{23-26}$ Iturin exhibit the antifungal activity against a number of fungal phytopathogens including $F$. graminearum, $F$. oxysporum, $R$. solani, Penicillium, Monilinia, Botrytis and Colletotricum. ${ }^{26,27-29}$

Surfactin: Surfactin are lipopeptides composed of $\beta$-hydoxyhepta cyclic depsipeptides with potential combinations of alanine, valine, leucine or isoleucine amino acids at positions 2, 4 and 7 in the cyclic depsipeptide moiety and variations of $\mathrm{C} 13$ to $\mathrm{C} 16$ in the chains of $\beta$-hydroxy fatty acids. ${ }^{30}$ Surfactin exhibits naturally antifungal activity and produce by Bacillus spp. according to the reported studies..$^{13,3}$ Surfactin inhibits the growth of various fungal phytopathogens includes Colletotrichum gloeosporiodes, $F$. verticillioides, $F$. graminearum, F. oxysporum, F.moniliforme and F.verticillioides. ${ }^{20}$ $32-34$

\section{Techniques used for the identification of Bacillus spp.} antifungal compounds

Bacillus spp. genomic research has shown that these bacteria contain genes that code for biological control-associated metabolites. Surfactin, fengycin, and iturin culture experiments are regularly conducted and have shown a myriad of antimicrobial substances capable of working against plant pathogenic fungi. To classify compounds that have antagonistic activity, these experiments use chromatography techniques and mass spectrometry. According to the current research on inhibition of $F$. graminearum and biosynthesis of their mycotoxin due to fengycin produce by Bacillus amyloliquefaciens. The Fengycin was purified and identified from the crude extract of Bacillus amyloliquefaciens by the HPLC techniques. Fengycin substantially impeded $F$. graminearum growth and also decreased the development of their mycotoxins. The authors inferred that $B$. amyloliquefaciens produce fengycin which potentially acts as an agent of biocontrol against $F$. graminearum and mycotoxins produced by this fungus can also be inhibited. ${ }^{12}$ Another study reported that the B. amyloliquefaciens successfully inhibit or control in vivo and in vitro environment the growth of $F$. graminearum. The antifungal compound was purified and identified as cyclo (L-Pro-D-Tyr) by spectroscopy. The first time inhibition analysis of cyclo (L-Pro-D-Tyr) against $F$. graminearum colonies was conformed. In vivo experiment by the use of cyclo(L-Pro-D-Tyr) the yield of the crops become $27 \%$ higher The authors inferred that $B$. amyloliquefaciens potentially act as an agent of biocontrol against $F$. graminearum as well as activities to promote plant growth of wheat. ${ }^{35}$

\section{Bacillus spp. screening techniques against fungal phytopathogens}

Traditionally, the effect of an organism or a material against the growth of a target organism is analyzed using bioassays. In a bioassay, in the presence of the antagonist, the organism is grown and its development tracked over time as opposed to that of experimental control. A region of growth inhibition around the inhibited microbe is characteristically shaped. To determine the impact of Bacillus spp. numerous bioassays have been performed against phytopathogens of fungi. The previously conducted analysis, which explicitly shows an antagonism between Bacillus spp. and fungal phytopathogens is noteworthy. ${ }^{36}$ According to another note able study, in which the biocontrol potential of rhizobacteria against the plant disease determined. The obtained result shows that Bacillus spp. was capable to reduce $67.34 \%$ of fungal colonies and also has the potential to improve the growth of the plant. ${ }^{37}$ Recently reported study on B. subtilis biocontrol against Rhizoctonia solani in pepper. The observations indicate that $B$. Subtilis was not only able to enable the mediated systemic resistance of pepper seedlings to induced wilt disease. $R$. Solani signaling pathway dependent on jasmonic acid but also produces antifungal compounds to prevent or even destroy mycelium formation. The results of this analysis offer innovative guidelines for the production of plant safety. ${ }^{38}$

\section{Conclusion}

The main strategies for the protection of crops from diseases are crop rotation, chemical pesticides, and chemical fungicides. Recently, due to the resistance of pathogens to fungicides and environmental issues, the biocontrol pattern of microbes through their antagonistic activity has become most important. This method is safe, environment friendly, and sustainable for the reduction of phytopathogens. Also at traceable speeds, high-resolution chromatography and mass spectrometry techniques can allow the discovery of new antagonistic molecules feasible. Specifically, if thoroughly explored, Bacillus will remove the existing commonly used control agents such as fungicides, harmful cultural activities of health and control phytopathogens in the ecosystem.

\section{Acknowledgments}

None.

\section{Funding}

None.

\section{Conflicts of interest}

The authors declare that there is no conflict of interest.

\section{References}

1. Ntushelo K, LedwabaLK, Rauwane ME, et al. The mode of action of Bacillus Species against Fusarium graminearum, Tools for investigation and future prospects. Toxins. 2019;11(10):606. 
2. Kant P, Reinprecht Y, Martin CJ, et al. Disease resistance / Pathology / Fusarium. Elsevier. 2011:00263-00264.

3. Ajayi OO, Bradleyb CA. Rhizoctonia solani: taxonomy, population biology and management of rhizoctonia seedling disease of soybean. Plant Pathology. 2018;67(1):3-17.

4. Mahmoud AF. Genetic variation and biological control of Fusarium graminearum isolated from wheat in assiut-Egypt. Plant Pathol J 2016;32(2):145-156.

5. Khan SA, Shah AH, Hussain A, et al. Identification and characterization of Penicillium chrysogenum T8 as potent plant growth promoting endophytic fungi. Fresen Environ Bull. 2019;28(6):4896-4902.

6. Javed A, Shah AH, Hussain A. Endophytic fungi promote growth of Tritium aestivum 1. under salinity induced stress. Fresen Environ Bull. 2019;28(6):4916-4922.

7. Wang X, Li Q, Sui J, et al. Isolation and characterization of antagonistic bacteria Paenibacillusjamilae HS-26 and their effects on plant growth. BioMed Research International. 2019:13.

8. Viveros OM, Jorquera MA, Crowley DE, et al. Mechanisms and practical considerations involved in plant growth promotion by rhizobacteria. $J$ Soil Sci Plant Nutr. 2010;10:293-319.

9. Teixeira LCRS, Peixoto RS, Cury JC, et al. Bacterial diversity in rhizosphere soil from antarctic vascular plants of admiralty bay, maritime Antarctica. ISME J. 2010;4(8):989-100.

10. Shafi J, Tian H, JiM. Bacillus species as versatile weapons for plant pathogens: a review. Biotechnology \& Biotechnological equipment. 2017;31(3):446-459.

11. Amin M, Rakhisi Z, AhmadyAZ. Isolation and identification of Bacillus Species from soil and evaluation of their antibacterial properties. Avicenna J ClinMicrobInfec. 2015;2(1):1-23.

12. Steller S, Vater J. Purification of the fengycinsynthetasemultienzyme system from Bacillus subtilis b213. J Chromatogr B Biomed SciAppl. 2000;737(1-2):267-275.

13. Hanif A, Zhang F, Li P, et al. Fengycin produced by Bacillus amyloliquefaciens FZB42 inhibits Fusarium graminearum growth and mycotoxins biosynthesis. Toxins. 2019;11(5):295.

14. Geetha L, Manonmani AM, PailyKP. Identification and characterization of a mosquito pupicidal metabolite of Bacillus subtilis sub sp. subtilisstrain. Appl Microbiol Biotechnol. 2010:86(6):1737-1744.

15. Deleu M, Paquot M, Nylander T. Fengycin interaction with lipid monolayers at the air-aqueous interface-implications for the effect off fengycin on biological membranes. J Coll Interface Sci. 2005;283(2):358365 .

16. Ongena M, Jourdan E, Adam A, et al. Surfactin and fengycinlipopeptides of Bacillus subtilis as elicitors of induced systemic resistance in plants. Environ Microbiol. 2007;9(4):1084-1090.

17. Zhang L, Sun C. Fengycins, cyclic lipopeptides from marine Bacillus subtilis strains, kill the plant-pathogenic fungus Magnaporthegrisea by inducing reactive oxygen species production and chromatin condensation. Appl Environ Microbiol. 2018;84(18):18-45.

18. Li XY, Yang JJ, Mao ZC, et al. Enhancement of biocontrol activities and cyclic lipopeptides production by chemical mutagenesis of Bacillus subtilis XF-1,a biocontrol agent of Plasmodiophorabrassicae and Fusarium solani. Indian J Microbiol. 2014;54(4):476-479.

19. Li L, Ma M, Huang R, et al. Induction of chlamydospore formation in Fusarium by cyclic lipopeptide antibiotics from Bacillus subtilis C2. J ChemEcol. 2012;38(8):966-974.

20. Fan H, Ru J, Zhang Y, et al. Fengycin produced by Bacillus subtilis 9407 plays a major role in the biocontrol of apple ring rot disease. Microbiol Res. 2017;199:89-97.
21. Kim PI, Ryu J, Kim YH, et al. Production of biosurfactantlipopeptidesiturin A, fengycin and surfactin from Bacillus subtilis CMB32 for control of Colletotrichumgloeosporides. J MicrobiolBiotechnol. 2010;20(1):138145.

22. Liu Y, Lu J, Sun J, et al. Membrane disruption and DNA binding of Fusarium graminearum cell induced by C16-Fengycin A produced by Bacillus amyloliquefaciens. Food Cont. 2019;102:206-213.

23. Ongena M, Jacques P. Bacilluslipopeptides: Versatile weapons for plant disease biocontrol. TrendsMicrobiol. 2008;16(3):115-124.

24. Nasir MN, Besson F. Interactions of the antifungal mycosubtilin with ergosterol-containing interfacial monolayers. Biochim Biophys Acta. 2012;1818(5):1302-1308.

25. Mater SM, El-Kazzaz SA, Waigh EE, et al. Antagonistic and inhibitory effect of Bacillus subtilis against certain plant pathogenic fungi. Biotechnology. 2009;8(1):53-61.

26. Meena KR, Saha D, Kumar R. Isolation and partial characterization of iturin like lipopeptides (a bio-control agent) from a Bacillus subtilis strain. Int J CurrMicrobiol App Sci. 2019;3(10):121-126.

27. Calvo H, Mendiara I, Arias E, et al. The role of iturin A from B.amyloliquefaciens BUZ-14 in the inhibition of the most common postharvest fruit rots. FoodMicrobiol. 2019;82:62-69.

28. Zalila-Kolsi I, Mahmoud AB, Ali H, et al. Antagonist effects of Bacillus spp. strains against Fusarium graminearum for protection of durum wheat(TriticumturgidumL.subsp. durum). Microbiol Res. 2016;192:148158.

29. Fujita S, Yokota K. Disease suppression by the cyclic lipopeptidesiturin A and surfactin from Bacillus spp. against Fusarium wilt of lettuce. J Gen Plant Pathol. 2019;85:44-48.

30. Zohora US, Ano T, Rahman MS. Biocontrol of Rhizoctonia solani K1 by iturinA producer Bacillus subtilis RB14 seed treatment in tomato plants. AdvMicrobiol. 2016;6(6):424-431.

31. Hue N, Serani L, Laprevote O. Structural investigation of cyclic peptidolipids from Bacillus subtilis by high energy tandem mass spectrometry. Rapid Commun Mass Spectrom. 2001;15(3):203-209.

32. Geissler M, Oellig C, Moss $\mathrm{K}$, et al. Hig performance thin layer chromatography (HPTLC) for the simultaneous quantification of the cyclic lipopeptidessurfactin, iturin A and fengycin in culture samples of Bacillus species. J Chromatogr B. 2017;1044-1045:214-224.

33. Snook ME, Mitchell T, Hinton DM, et al. Isolation and characterization of Leu7-surfactin from the endophytic bacterium Bacillus mojavensis RRC 101, a biocontrol agent for Fusarium verticillioides. J Agric Food Chem. 2009;57(10):4287-4292.

34. Dunlap CA, Schisler DA, Price NP, et al. Cyclic lipopeptide profile of three Bacillus subtilis strains; antagonists of Fusarium head blight. $J$ Microbiol. 2011;49(4):603-609.

35. Vitullo D, Di Pietro A, Romano A, et al. Role of new bacterial surfactins in the antifungal interaction between Bacillus amyloliquefaciens and Fusarium oxysporum. Plant Pathol. 2012;61(4):689-699.

36. Jamal Q, Monkhung S, Munir S, et al. Identification of cyclo(L-Pro-DTyr) from Bacillus amyloliquefaciens Y1 exhibiting antifungal activity against Fusarium graminearum to control crown rot in wheat. Applied ecology and environmental research. 2019;17(3):6299-6314.

37. Zhao Y, Selvaraj JN, Xing F, et al. Antagonistic action of Bacillus subtilis strain SG6 on Fusarium graminearum. PLoS ONE. 2014; 9:e92486.

38. Dukare A, Paul S, Arambam A. Isolation and efficacy of native chitinolyticrhizobacteria for biocontrol activities against fusarium wilt and plant growth promotion in pigeon pea (Cajanuscajan L.), Egyptian Journal of Biological Pest Control. 2020;30:56. 